\title{
Conselhos Municipais: participação, efetividade e institucionalização - a influência do contexto político na dinâmica dos conselhos - os casos de Porto Alegre e Salvador*
}

\section{City Cuncils: participation, efetiveness and institutionalization - the influence of political context in the dynamics of councils. The cases of Porto Alegre and Salvador}

\author{
Antonio Sergio Araújo Fernandes ${ }^{1}$
}

\begin{abstract}
Resumo
Neste artigo são abordadas três categorias de análise que vêm sendo desenvolvidas pela literatura sobre conselhos municipais no Brasil, quais sejam: a natureza da participação dos conselheiros, a efetividade dos conselhos e o desenho institucional. Nele, desenvolve-se a hipótese da influência do contexto político local na formação e trajetória dos conselhos. Desse modo, a forma como se desenvolveu o contexto político em Porto Alegre e Salvador influenciou a formação dos dois conselhos em termos de participação, efetividade e institucionalização. Na pesquisa, tem-se um estudo comparado dos conselhos municipais de saúde nas cidades de Salvador e Porto Alegre entre os anos 2005 e 2007, com o objetivo de mostrar que a diferença na dinâmica de funcionamento e organização dos conselhos foi influenciada por contextos políticos distintos do poder municipal experimentados nas duas cidades entre os anos 90 e a primeira metade da primeira década do século XXI.
\end{abstract}

Palavras-chave: conselhos municipais; contexto político; participação; efetividade; desenho institucional.

\begin{abstract}
The paper issues three categories of analysis in the literature of local councils in Brazil: the nature of the participation of councilors, the effectiveness of councils and the institutional design. The paper argues the hypothesis of the influence of the local political context in the formation and trajectory of councils. The political context in Porto Alegre and Salvador has influenced the two councils differently in terms of participation, effectiveness and institutionalization. The research is a comparison of the Local Health Councils in the cities of Salvador and Porto Alegre between 2005 and 2007, and shows that the difference in the dynamics of the functioning and organization of councils have influenced different local political contexts in local power experienced in the two cities between the nineteen nineties and the first five years of the twenty-first century.
\end{abstract}

Keywords: City councils; political context, participation; efectiveness, institutional design

\section{Introdução}

Muito se produziu sobre conselhos municipais no Brasil nos últimos 15 anos. Ainda que os trabalhos sejam de grande importância e tragam achados relevantes para a pesquisa sobre esse objeto, lacunas de explicação persistem. Os trabalhos organizados por Avritzer (2004; 2007) sobre "A Participação em São Paulo" e "A Participação no Nordeste" trazem estudos que incorporam algumas dimensões de análise, como: cultura política e desempenho dos conselhos (AVRITZER, 2007); institucionalização dos conselhos (FARIA, 2007); efetividade da participação dos conselheiros (CUNHA, 2007); relação entre a existência e o funcionamento do

\footnotetext{
* Este artigo apresenta os resultados do Projeto de Pesquisa "Elites Dirigentes e Participação Política: Conselhos Municipais em Capitais Metropolitanas" que teve auxílio do CNPq com o processo no 400671/2007-7 e da FAPESP com o processo 2005/00745-0. O projeto contou com dois bolsistas de iniciação científica do CNPq e da Propesq/UFRN entre os anos de 2007 e 2009, Tiago César Medeiros e Geisa Maria Rodrigues de Vasconcelos. Uma versão deste texto foi apresentada no 14을 CISO - Encontro de Ciências Sociais do Norte e Nordeste em setembro de 2009, em Recife/PE.

${ }^{1}$ Doutor em Ciência Política pela Universidade de São Paulo, Professor Adjunto e Pesquisador do Programa de Pós-Graduação em Administração da Universidade Federal do Rio Grande do Norte - UFRN. Endereço: Programa de Pós-Graduação em Administração - PPGA Edifício do Centro de Ciências Sociais Aplicadas - CSSA - Campus Universitário - Bairro Lagoa Nova - Caixa Postal 1570 - CEP 59072-970 - Natal/RN - Brasil. E-mail: asaferna@uol.com.br.
} 
conselho com variáveis tais como: competição política, rede associativa local, tendência programática do partido governista (BANDEIRA, 2007). Coelho e Veríssimo (2004 analisam o caso do conselho de saúde no município de São Paulo, observando a relação entre os vínculos dos conselheiros com o grupo políticopartidário que ocupa o poder. Outros trabalhos importantes nessa área são o estudo de Perissinotto; Fuks, Ribeiro (2003), que trata dos conselhos municipais em Curitiba com base em cultura política, e o de Fuks (2004), que analisa o processo decisório de conselhos municipais também em Curitiba, com base na distribuição da influência política entre os diversos segmentos representados.

Este trabalho trata empiricamente de três categorias de análise dos estudos acima mencionados, quais sejam, a natureza da participação dos conselheiros, a efetividade dos conselhos (intensidade e natureza das deliberações) e o seu desenho institucional (regras e procedimentos que o regem). Propõe-se a complementar as explicações acima mencionadas sobre os conselhos municipais desenvolvendo uma hipótese sobre a influência do contexto político local na formação e trajetória dos conselhos municipais. A forma como se desenvolveu a disputa da elite local pelo poder político municipal influenciou a formação e a trajetória dos conselhos em termos de efetividade, participação dos membros e institucionalização. $O$ argumento que fundamenta tal hipótese é de que o momento crítico de origem dos conselhos, ao longo da década de 90, foi influenciado diretamente pelo contexto político de disputa de poder da elite política local. Para tanto o trabalho apresenta os resultados de um estudo comparado dos conselhos de saúde das cidades de Salvador e Porto Alegre, cidades que possuíram, ao longo dos anos 90 e início do século XXI, distintos contextos políticos de ocupação do poder municipal. .

A hipótese aqui esboçada é de que, no momento atual, os conselhos municipais das capitais estudadas, Salvador e Porto Alegre, apresentam diferenças em termos de efetividade, processo de participação e desenho institucional. Estas três categorias apresentam uma intensidade maior no Conselho de Saúde de Porto Alegre comparativamente ao de Salvador. Tal diferença relaciona-se às trajetórias recentes de estruturação e organização dos conselhos, sobretudo em um momento crítico específico, situado entre o marco constitucional de 1988 e o início da década de 90 . Isso se deve ao fato de ocorrerem diferenças no contexto onde as elites políticas locais disputaram o poder. Configurações políticas diversas estabeleceram-se gerando trajetórias heterogêneas de organização e estruturação dos conselhos municipais. Em Porto Alegre uma elite política voltada a questões relacionadas a participação e controle social como plataforma política foi hegemônica no município. Em Salvador, uma elite política polarizada em torno de uma liderança pessoal e conservadora, pouco afeita a questões de participação e controle social, terminou por exercer o poder no município, ao longo dos anos 90. Com isso terminou por tornar seu conselho municipal de saúde menos autônomo que o de Porto Alegre.

Para desenvolver o argumento do ponto de vista conceitual será utilizado o conceito de 'momento crítico' (critical junctures) - muito usado, sobretudo na literatura que contempla o conceito de dependência de trajetória (path dependency). O conceito de momento crítico servirá como apoio para observar como, após a Constituição de 1988 e no início dos anos 90, a diferença no contexto de disputa política das elites locais levou os conselhos municipais de Salvador e Porto Alegre a trajetórias diversas em sua organização e estrutura.

$\mathrm{O}$ artigo está dividido em cinco seções, contando-se com esta introdução. Na seção "A literatura sobre conselhos municipais no Brasil no que se refere à participação, efetividade e institucionalização", discute-se sobre o estudo com o qual este trabalho pretende dialogar diretamente em termos de abordagem de análise, qual seja, o trabalho de Avritzer (2007). A seção "Os Conselhos de Saúde de Salvador e Porto Alegre (2005-2007): efetividade, participação e desenho institucional" traz os resultados da pesquisa comparada sobre os conselhos municipais de saúde nas capitais de Porto Alegre e Salvador entre os anos de 2005 e 2007, referindo-se aos fatores anteriormente citados. Na seção "O momento crítico em Porto Alegre e Salvador: o contexto de disputa política nas duas Cidades", aborda-se o enfoque conceitual da hipótese aqui esboçada: o conceito de "momento crítico'. Com base nisso esta seção também busca analisar o momento crítico de disputa das elites políticas locais que terminaram por diferenciar a trajetória de organização e estruturação dos conselhos municipais de Saúde em Porto Alegre e Salvador. Nas considerações finais do trabalho, busca-se pontuar a questão da participação social no Brasil com diferenças marcantes nos contextos políticos locais. 
A literatura sobre conselhos municipais no Brasil no que se refere à participação, efetividade e institucionalização

Muito se produziu sobre conselhos municipais no Brasil nos últimos 15 anos. E, aqui, pode ser estabelecida uma divisão acerca destes estudos. Um primeiro conjunto de trabalhos situa-se no decorrer da década de 90 do século XX, e é ainda oriundo da inércia analítica militante da literatura dos anos 80 sobre participação social e movimentos sociais no Brasil. ${ }^{2}$ Tem-se como contribuições importantes, entre outras, Gohn (2001); Raichelis (2000); Carvalho (1995); Dal Poz e Pinheiro (1998); Tatagiba (2002); Tótora e Chaia (2002); Andrade (2002); Carvalho et al. (1999); Castro (1999). A maior parte dos trabalhos sobre os conselhos gestores procura observar de modo descritivo seus arranjos organizacionais, além do grau de organização do movimento popular, sindical e de usuários que participam dos conselhos, e também o grau de engajamento da liderança política profissional, Este último aspecto integra os estudos de Cortes (1998; 1995), que considera de grande importância a ação das lideranças políticas como uma variável chave no entendimento do funcionamento bem sucedido dos conselhos municipais. Com base no conceito de policy community, a autora mostra como, no caso dos Conselhos Municipais de Saúde da Região Metropolitana de Porto Alegre, a presença de lideranças políticas e de representantes profissionais nos conselhos comprometidos com a participação dos movimentos sociais termina por estimular o engajamento da sociedade civil.

Entretanto, é na primeira década ${ }^{3}$ do século XXI que os trabalhos sobre conselhos municipais proliferaram mais proficuamente do ponto de vista de achados e análises empíricas. Com um destes, especificamente, se procurará, aqui, dialogar. Referimo-nos a "Participação no Nordeste", trabalho organizado por Avritzer (2007). Este estudo apresenta achados importantes no que diz respeito aos conselhos municipais quanto a natureza da participação dos conselheiros, sua efetividade (natureza das deliberações) e o seu desenho institucional (regras e procedimentos que o regem).

O trabalho envolveu uma rede de pesquisadores no projeto denominado "Participação e Distribuição nas Políticas Públicas do Nordeste". Efetuou-se uma análise comparativa da qualidade da organização, estrutura e processo de participação dos conselhos municipais de saúde e da criança e do adolescente, em municípios dos seguintes estados: Bahia (16 conselhos analisados em 9 municípios, incluindo Salvador), Pernambuco (14 conselhos analisados em 7 municípios, incluindo Recife) e Ceará (8 conselhos analisados em 6 municípios, incluindo Fortaleza).

Como síntese conclusiva geral dos achados empíricos da pesquisa, Avritzer (2007) afirma que, nos estados de Pernambuco, Bahia e Ceará, há diferenças de 'performance' no que se refere à participação, à efetividade e à institucionalização dos conselhos municipais. Em Pernambuco, observa-se uma maior expressão, com mais associativismo e organização dos conselhos e deliberações que influenciam mais a política local. Na Bahia, baixo desempenho, com diferenças entre os conselhos, sobretudo das capitais, comparativamente aos do interior, em todos estes três aspectos. Observam-se, também, diferenças entre os conselhos de capitais: Recife apresenta melhor desempenho; e Salvador, pior. Ou seja, em Recife, os conselhos de saúde e da criança e do adolescente são efetivos, com influência na política municipal; já em Salvador, são quase protocolares (apenas encaminham documentos). A presidência dos conselhos é dada ao Secretário no caso de Salvador e em Recife, os presidentes são eleitos em plenária.

O estudo organizado por Avritzer sobre a "Participação no Nordeste", ora comentado, é profundamente importante por tentar investir em uma problemática similar àquela levantada por Putnam (1996) sobre a Itália, qual seja, as tradições cívicas acumuladas que produzem capital social implicam melhor desempenho das instituições descentralizadas italianas ao longo da história. Apesar disso, Avritzer e seus colaboradores necessitariam de uma etapa seguinte a este projeto, para realizar uma comparação inter-regional no país visando obter inferências sobre a diferença de desempenho dos conselhos entre as regiões, se elas existem, onde e por

\footnotetext{
${ }^{2}$ A revisão de literatura sobre participação social e movimentos sociais no Brasil nos anos 80 é exaustiva e minuciosamente efetuada nos trabalhos de Fernandes (2004); Doimo (1995); Fernandes e Bonfim (2005) e na coletânea organizada por Bandeira, Lubambo e Melo (2005), entre outros.

${ }^{3}$ Neste período, destacam-se os trabalhos de Coelho e Veríssimo (2004: 105-122), já citado, e o de Santos Jr., Ribeiro e Azevedo (2004).
} 
que existem. E, evidentemente, baseando-se nisso, observar se há duas culturas políticas no país, uma com grau cívico maior, tal como Putnam verificou no caso italiano.

O que se propõe, aqui, é a observação comparativa de dois casos de desempenho de conselho de saúde. Porém, não com o intuito de estabelecer explicações que mostrem diferenças entre 'duas culturas políticas', mas por meio de fatos relevantes que influenciaram o desempenho dos conselhos e que possam explicar a diferença de desempenho, em termos de participação, do conselho municipal de saúde de Salvador em relação ao de Porto Alegre. A hipótese que se levanta aqui, já expressa anteriormente, é de que a elite política à frente do município influenciou decisivamente no comportamento do conselho como será visto a seguir.

\section{Os Conselhos de Saúde de Salvador e Porto Alegre (2005-2007): efetividade, participação e desenho institucional}

\section{Participação e Efetividade}

Os dados aqui apresentados foram obtidos com o exame das atas de reuniões dos Conselhos Municipais de Saúde em Salvador e Porto Alegre nos anos entre 2005 e 2007. Os elementos observados nas atas para a pesquisa foram: 1. a frequência dos conselheiros: porcentagem de presença nas reuniões; 2 . o tema discutido nas reuniões. A totalidade de assuntos discutidos nas reuniões foi dividida em quatro temas: recursos; políticas de saúde; controle e fiscalização; organização interna do conselho; gestão da saúde no município; 3. o ator que inicia a discussão dos assuntos (se governo, se trabalhadores, se usuários etc.); 4. se os assuntos foram deliberados ou não.

\section{Participação}

O primeiro elemento a ser observado na participação é a frequência dos conselheiros às reuniões. Na Tabela 1, verifica-se que em Salvador, nos três anos da série entre 2005 e 2007, a maior presença foi de membros externos ao conselho, sem representação formal - os únicos que sempre estiveram presentes em quase metade ou pouco mais da metade das reuniões nos três anos. Os demais membros - e que são membros formais - têm presença nas reuniões demasiadamente baixa nos três anos observados. Diferentemente de Salvador, em Porto Alegre a presença maciça dos membros do conselho é de usuários. Em todos os três anos analisados, eles estiveram presentes em mais da metade das reuniões.

\section{Tabela 1 - Frequência dos Conselheiros às Reuniões}

\begin{tabular}{lcccccc}
\hline & \multicolumn{2}{c}{$\mathbf{2 0 0 5}$} & \multicolumn{2}{c}{$\mathbf{2 0 0 6}$} & \multicolumn{2}{c}{$\mathbf{2 0 0 7}$} \\
\hline Presença & Salvador & Porto Alegre & Salvador & Porto Alegre & Salvador & Porto Alegre \\
\hline Usuários & $\%$ & $\%$ & $\%$ & $\%$ & $\%$ & $\%$ \\
\hline Trabalhadores & 17,8 & 14,0 & 19,3 & 17,8 & 14,0 & 21,5 \\
\hline Governo & 6,8 & 1,0 & 11,0 & 2,0 & 7,3 & 3,0 \\
\hline Prestadores & 4,5 & 8,7 & 4,9 & 7,7 & 0,6 & 5,1 \\
\hline Externos & 51,9 & 3,7 & 40,8 & 1,5 & 45,8 & 2,2 \\
\hline Não identificados & 0,0 & 0,0 & 0,0 & 0,0 & 4,5 & 0,0 \\
\hline Missing & 0,0 & 0,0 & 0,0 & 0,0 & 0,0 & 0,0 \\
\hline Total & 100 & 100 & 100 & 100 & 100 & 100 \\
\hline
\end{tabular}

A Tabela 2 indica que, no caso de Salvador, o governo e os membros externos são os principais pautadores das reuniões; ainda que no ano de 2007, os prestadores e os usuários tenham tido maior participação no início dos 
assuntos, perfazendo 50\% do total dos assuntos iniciados no conselho neste ano por estes dois atores. Já em Porto Alegre, os usuários sempre foram os responsáveis por iniciar a maioria dos assuntos nas reuniões.

Tabela 2 - Membro que inicia a discussão

\begin{tabular}{lcccccc}
\hline & \multicolumn{2}{c}{$\mathbf{2 0 0 5}$} & \multicolumn{2}{c}{2006} & \multicolumn{2}{c}{$\mathbf{2 0 0 7}$} \\
\hline $\begin{array}{l}\text { Quem inicia a } \\
\text { discussão }\end{array}$ & Salvador & Porto Alegre & Salvador & Porto Alegre & Salvador & Porto Alegre \\
\hline \multicolumn{1}{l}{$\%$} & $\%$ & $\%$ & $\%$ & $\%$ & $\%$ \\
\hline Usuários & 14,3 & 54,8 & 3,4 & 56,2 & 25,0 & 32,3 \\
\hline Trabalhadores & 14,3 & 3,2 & 6,9 & 3,1 & 0,0 & 3,2 \\
\hline Governo & 30,6 & 4,8 & 31,0 & 4,7 & 12,5 & 6,5 \\
\hline Prestadores & 2,0 & 1,6 & 3,4 & 0,0 & 25,0 & 0,0 \\
\hline Externos & 18,4 & 29,0 & 44,8 & 29,7 & 37,5 & 35,5 \\
\hline $\begin{array}{l}\text { Não } \\
\text { identificados }\end{array}$ & 0,0 & 0,0 & 0,0 & 0,0 & 0,0 & 0,0 \\
\hline Missing & 20,4 & 6,5 & 10,3 & 6,2 & 0,0 & 22,6 \\
\hline Total & 100 & 100 & 100 & 100 & 100 & 100 \\
\hline
\end{tabular}

\section{Efetividade}

Na Tabela 3 verifica-se que, no Conselho de Saúde de Porto Alegre, a maior parte dos principais assuntos discutidos diz respeito aos temas "Controle e Fiscalização" e "Gestão da Saúde no Município"; ou seja, os assuntos mais relacionados à atividade finalística do conselho. No Conselho Municipal de Saúde de Salvador, observa-se que, dos assuntos discutidos, o tema mais frequente e majoritário nos três anos foi "organização interna do conselho". O segundo tema mais discutido pelo CMS de Salvador refere-se à gestão de saúde. Já o tema "Controle e Fiscalização" foi muito pouco discutido em Salvador ao longo das reuniões ocorridas neste triênio.

Tabela 3 - Assuntos Discutidos pelos Conselhos

\begin{tabular}{lcccccc}
\hline & \multicolumn{2}{c}{ 2005 } & \multicolumn{2}{c}{ 2006 } & \multicolumn{2}{c}{ 2007 } \\
\hline Tema & Salvador & Porto Alegre & Salvador & Porto Alegre & Salvador & Porto Alegre \\
\hline Recursos & $\%$ & $\%$ & $\%$ & $\%$ & $\%$ & $\%$ \\
\hline Políticas de Saúde & 6,1 & 6,5 & 3,4 & 1,6 & 12,5 & 12,9 \\
\hline Controle e Fiscalização & 18,4 & 6,5 & 3,4 & 9,4 & 0,0 & 9,7 \\
\hline $\begin{array}{l}\text { Organização Interna do } \\
\text { Conselho }\end{array}$ & 0,0 & 37,1 & 10,3 & 51,6 & 25,0 & 25,8 \\
\hline $\begin{array}{l}\text { Gestão da Saúde no } \\
\text { Município }\end{array}$ & 24,7 & 14,5 & 37,9 & 0,0 & 50,0 & 6,5 \\
\hline Outros & 2,0 & 22,6 & 17,2 & 10,9 & 12,5 & 12,9 \\
\hline Missing & 12,2 & 3,2 & 0,0 & 7,8 & 0,0 & 16,1 \\
\hline Total & 100 & 100 & 100 & 100 & 100 & 100 \\
\hline
\end{tabular}


No que tange à deliberação dos assuntos discutidos em reuniões, é flagrante a diferença entre Porto Alegre e Salvador, como mostra a Tabela 4. Do total de assuntos discutidos nos dois conselhos, em Porto Alegre a grande maioria destes foi deliberada para encaminhamento; diferentemente de Salvador, onde muito pouco do que se discutiu foi deliberado para encaminhamento. Ou seja, o grau de efetividade do conselho municipal de saúde de Porto Alegre é maior do que o de Salvador.

Tabela 4- Total dos assuntos discutidos que foram deliberados

\begin{tabular}{lcccccc}
\hline & \multicolumn{2}{c}{2005} & \multicolumn{2}{c}{2006} & \multicolumn{2}{c}{$\mathbf{2 0 0 7}$} \\
\hline Deliberação & Salvador & Porto Alegre & Salvador & Porto Alegre & Salvador & Porto Alegre \\
\hline & $\%$ & $\%$ & $\%$ & $\%$ & $\%$ & $\%$ \\
\hline Sim & 69,4 & 79,0 & 89,7 & 76,6 & 50,0 & 71,0 \\
\hline Não & 18,4 & 14,5 & 10,3 & 23,4 & 50,0 & 22,6 \\
\hline Missing & 12,2 & 6,5 & 0,0 & 0,0 & 0,0 & 6,4 \\
\hline Total & 100 & 100 & 100 & 100 & 100 & 100 \\
\hline
\end{tabular}

A Tabela 5 mostra que, em Porto Alegre, dos 123 assuntos, nos 6 temas agregados, 40 foram iniciados pelos usuários no tema "Controle e fiscalização". Já o segundo maior tema foi "Gestão de Saúde do Município", tendo sido provocado inicialmente 12 vezes pelo ator externo. Isso corrobora o que está expresso na Tabela 2, na qual consta que quem mais inicia assunto nas reuniões do Conselho Municipal de Saúde de Porto Alegre são os usuários, em primeiro lugar; e em segundo, os atores externos. Há também uma consonância com a Tabela 3, já que os principais temas discutidos pelo CMS/POA foram "Controle e Fiscalização" e "Gestão da Saúde no Município".

Tabela 5 - CMS/POA: Tema X Membro iniciador (2005; 2006; 2007)

\begin{tabular}{lcccccc}
\hline \multirow{2}{*}{ Tema } & \multicolumn{7}{c}{ Membro Iniciador } \\
\cline { 2 - 7 } Recurso & Usuário & Trabalhador & Governo & Prestador & Externo & Total \\
\hline Políticas de Saúde & 4 & 0 & 0 & 0 & 2 & 6 \\
\hline Controle e Fiscalização & 4 & 1 & 0 & 0 & 4 & 9 \\
\hline Organização Interna do Conselho & 8 & 0 & 1 & 0 & 1 & 10 \\
\hline Gestão da Saúde no Município & 4 & 2 & 1 & 0 & 12 & 19 \\
\hline Outros & 6 & 1 & 2 & 0 & 16 & 25 \\
\hline Total & 66 & 4 & 8 & 1 & 44 & 123 \\
\hline
\end{tabular}

A Tabela 6 abaixo mostra que, no Conselho Municipal de Saúde de Salvador, no triênio, dos 73 assuntos dentro dos 6 temas agregados, 13 foram iniciados pelo governo no tema "organização interna do conselho". O segundo maior tema entre os assuntos iniciados foi, novamente, "organização interna do conselho" - provocado sete vezes inicialmente pelos usuários. Também aqui constata-se uma consonância com a Tabela 2, segundo a qual quem mais inicia assunto nas reuniões do Conselho Municipal de Saúde de Salvador é o governo. Nota-se também uma consonância com a Tabela 3, pois o assunto mais iniciado no CMS/SSA foi "organização interna do conselho". 
Tabela 6-CMS/SSA: Tema X Membro iniciador (2005; 2006; 2007)

\begin{tabular}{lcccccc}
\hline \multirow{2}{*}{ Tema } & \multicolumn{5}{c}{ Membro Iniciador } \\
\cline { 2 - 7 } & Usuário & Trabalhador & Governo & Prestador & Externo & Total \\
\cline { 2 - 7 } & \multicolumn{1}{c}{ Usuário } & Trabalhador & Governo & Prestador & Externo & Total \\
\hline Recurso & 1 & 0 & 3 & 0 & 1 & 5 \\
\hline Políticas de Educação & 0 & 3 & 1 & 0 & 6 & 10 \\
\hline Controle e Fiscalização & 0 & 0 & 0 & 0 & 5 & 5 \\
\hline Organização Interna do Conselho & 7 & 5 & 13 & 4 & 3 & 32 \\
\hline Gestão da Educação no Município & 2 & 1 & 7 & 0 & 6 & 16 \\
\hline Outros & 0 & 0 & 1 & 0 & 4 & 5 \\
\hline Total & 10 & 9 & 25 & 4 & 25 & 73 \\
\hline
\end{tabular}

\section{Institucionalização}

No que se refere à ordem cronológica de criação dos conselhos observa-se no Quadro 1 que ambos foram criados no início dos anos 90, quando se passa a exigir legalmente a existência de conselhos para a execução das políticas sociais. O CMS/SSA, apesar de criado no ano de 1990, sofreu posterior mudança legal em 2000.

Quadro 1 - Legislação e Ano de Criação do CMS

\begin{tabular}{ccc}
\hline & Porto Alegre & Salvador \\
\hline Lei e Ano de Criação & $277 / 1992$ & $4103 / 1990$ e 5845/2000 \\
\hline
\end{tabular}

O Quadro 2 indica que os conselhos de Porto Alegre e Salvador foram criados posteriormente à legislação municipal que os dá existência. No caso de Porto Alegre, o CMS/POA foi criado ainda na década de 1990, no ano de 1997; e em Salvador, apenas na primeira década do século XXI, no ano de 2005. Até então o instrumento que regia a estrutura e o funcionamento dos conselhos era a própria legislação municipal de criação. Percebe-se que houve um processo longo de maturação para a criação do regimento interno, após a abertura e funcionamento pleno do conselho municipal em ambos os casos; sendo, entretanto, bem mais longo no caso de Salvador.

Quadro 2 - Existência e Ano de Criação do Regimento Interno do CMS

\begin{tabular}{ccc}
\hline & Porto Alegre & Salvador \\
\hline Regimento Interno & Sim & Sim \\
\hline Ano de Elaboração & 1997 & $2005^{*}$ \\
\hline
\end{tabular}

*Aprovado em 2005, regulamentado na Lei 7067/2006

No Quadro 3 a seguir, nota-se que a estrutura e o funcionamento dos conselhos são semelhantes em ambos os casos: os dois conselhos são compostos de plenário, mesa diretora, secretaria executiva e comissões técnicas ou temáticas. A importância destas últimas está no fato de que informam e dão parecer sobre os temas específicos para serem apreciados em plenário. 
Quadro 3 - Estrutura de Funcionamento do CMS

\begin{tabular}{|c|c|c|}
\hline Estrutura de Funcionamento & Porto Alegre & Salvador \\
\hline Plenário & Sim & Sim \\
\hline Mesa Diretora & Sim & Sim \\
\hline Secretaria Executiva & Sim & Sim \\
\hline Comissões Técnicas, temáticas e ou de trabalho & Sim & Sim \\
\hline
\end{tabular}

As reuniões ordinárias dos dois conselhos municipais ocorrem periodicamente, mas com intervalos de tempo diferentes, como se pode perceber no Quadro 4 abaixo. As reuniões ordinárias do conselho são quinzenais em Porto Alegre e, mensais, em Salvador.

Quadro 4 - Frequência e Local das Reuniões do CMS

\begin{tabular}{lcc}
\hline Frequência e Local & Porto Alegre & Salvador \\
\hline Frequência das reuniões & quinzenal & mensal \\
\hline Local onde ocorre & SMS & Espaço cedido pela Prefeitura \\
\hline
\end{tabular}

No Quadro 5 tem-se o número de reuniões por ano entre 2005 e 2007. Percebe-se que o CMS/POA reúne-se regularmente, com poucas variações, para mais ou para menos, no número de reuniões previsto anualmente. Já o CMS/SSA apresenta uma frequência de reuniões muito irregular, recorrendo, no ano de 2005, a muitas sessões extraordinárias. No ano de 2007, o CMS/SSA teve muito poucas reuniões ordinárias, apenas um terço do que é previsto ao longo do ano.

Quadro 5 - Número de plenárias realizadas pelo CMS (2005-2006-2007)

\begin{tabular}{ccc}
\hline \multirow{2}{*}{ Ano } & \multicolumn{3}{c}{ Número de Plenárias } \\
\cline { 2 - 3 } & Porto Alegre & Salvador \\
\hline 2005 & 26 & 25 \\
\hline 2006 & 26 & 16 \\
\hline 2007 & 22 & 4 \\
\hline
\end{tabular}

Os conselhos possuem números diferentes em termos de membros, porém, distribuem seus assentos entre os representantes de modo mais ou menos parecido, respeitando a paridade constitucional (Quadro 6). A representação dos usuários possui uma proporção de assentos ligeiramente diferente, sendo maior (50\% dos assentos) no CMS/POA. A representação do Governo é bem maior em Salvador do que em Porto Alegre em termos proporcionais. Os prestadores de serviço têm diferença na proporção de representação, sendo maior esta no CMS/SSA. A representação do governo é maior proporcionalmente no CMS/SSA do que no CMS/POA, e a representação dos trabalhadores de saúde é ligeiramente menor proporcionalmente no CMS/POA, em relação ao CMS/SSA. Ou seja, há uma representação maior do governo em detrimento de uma representação menor dos trabalhadores e prestadores no caso de Salvador em relação a Porto Alegre. Cabe ressaltar que esta estrutura no CMS/SSA com 25 membros representantes passou a vigorar a partir de $2006 \mathrm{com}$ a Lei 7017/2006. Até então o CMS/SSA tinha uma representação de 16 membros. 
Quadro 6 - Número de membros por grupo representativo do CMS

\begin{tabular}{lcccc}
\hline \multirow{2}{*}{ Membros } & \multicolumn{2}{c}{ Porto Alegre } & \multicolumn{2}{c}{ Salvador } \\
\cline { 2 - 5 } & Não & $\mathbf{\%}$ & N & \% \\
\hline Governo & 9 & 11,5 & 9 & 25 \\
\hline Prestadores de serviços de saúde & 6 & 7,7 & 4 & 11,1 \\
\hline Trabalhadores e Profissionais de saúde & 24 & 30,8 & 6 & 33,3 \\
\hline Usuários & 39 & 50,0 & 11 & 30,6 \\
\hline Total & 78 & 100,0 & 36 & 100,0 \\
\hline
\end{tabular}

A presidência do conselho é escolhida, em Salvador e em Porto Alegre, de modo igual (Quadro 7); ou seja, por meio de eleição entre os membros em reunião plenária. Cabe ressaltar que a eleição para Presidente do CMS/SSA tinha sido suspensa em 2000 por meio da Lei $n^{\circ} 5.845 / 2000$. A partir daquele ano até 2006, o Secretário de Saúde era o Presidente do Conselho. No entanto, a Lei 7.017/2006 alterou o artigo $5^{\circ}$ da Lei $\mathrm{n}^{\circ}$. 5.845/2000 determinando que o Presidente do CMS/SSA fosse eleito pelos membros do conselho municipal de saúde em reunião plenária.

Quadro 7 - Presidente do Conselho

\begin{tabular}{lcc}
\hline & Porto Alegre & Salvador \\
\hline Secretário Municipal de Saúde & Não & Não \\
\hline Eleito em plenário & Sim & Sim \\
\hline
\end{tabular}

A duração do mandato dos conselheiros é de 6 anos, no caso do CMS/POA, sem possibilidade de recondução; enquanto em Salvador é de apenas 2 anos, com possibilidade de recondução - Quadro 8.

Quadro 8 - Duração do mandato dos conselheiros

\begin{tabular}{ccc}
\hline & Porto Alegre & Salvador \\
\hline Duração do mandato dos conselheiros & 6 anos & 2 anos \\
\hline
\end{tabular}

Síntese Analítica, os aspectos tratados até aqui mostram que o CMS/POA é mais participativo e efetivo que o CMS/SSA. Se não vejamos:

1. No CMS/SSA os conselheiros vão pouco às reuniões, uma vez que a maior presença nas reuniões do CMS/SSA são de membros externos (visitantes), que não são conselheiros. NO CMS/POA, diferentemente de Salvador, os conselheiros costumam freqüentar as reuniões, sobretudo os representantes dos usuários, que se mostram como os mais presentes.

2. No CMS/POA, quem mais inicia os assuntos para discussão em reuniões são os usuários, ao contrário do $\mathrm{CMS} / \mathrm{SSA}$, onde o principal pautador das reuniões é o governo e os membros externos (visitantes).

3. No CMS/POA os assuntos mais discutidos são os que se referem ao campo de atuação efetiva do conselho, quais sejam "Controle e Fiscalização" e "Gestão da Saúde no Município". Já o CMS/SSA, gasta maior do seu tempo em discutir sua organização interna, ainda que chegue a tratar de "Controle e Fiscalização", porém em muito menos intensidade que o CMS/POA.

4. O CMS/POA se mostra mais efetivo que o CMS/SSA, pois em Porto Alegre a grande maioria dos assuntos que são discutidos em reuniões são deliberados para encaminhamento enquanto que em Salvador, quase nada do que é discutido é deliberado. 
No que se refere à institucionalização ambos se encontram em estágios parecidos, porém com um detalhe de diferença: a paridade de representação o CMS/SSA tem uma representação maior do governo e menor dos trabalhadores e prestadores em relação ao CMS/POA.

Por que estas diferenças entre estes dois conselhos? Por que em Porto Alegre o seu CMS é mais participativo e efetivo e tem instituições que favorecem uma maior autonomia do conselho e em Salvador não?

Como se apontou na introdução do artigo, a explicação para esta diferença está nos diferentes momentos críticos experimentados pelas duas cidades no período pós-constitucional de 1988. Em Porto Alegre observa-se que uma elite política afeita aos processos de participação política faz reforçar isso na política local. Em Salvador, diferentemente, uma elite política conservadora e pouco afeita aos processos de participação política resiste e esbarra num reforço à rota participativa dos conselhos pós-constituição de 1988.

\section{O momento crítico em Porto Alegre e Salvador: o contexto de disputa política nas duas Cidades}

\section{O momento crítico}

O conceito de momento crítico será abordado aqui com base nos trabalhos de Lipset e Rokkan (1967) e Collier e Collier (1991). De acordo com Lipset e Rokkan (1967), a ideia de escolhas cruciais e seus legados, que podem ser chamados de momentos críticos, tem foco principal sobre circunstâncias decisivas na vida política, nas quais ocorrem transições que estabelecem certas direções de mudança e excluem outras, num caminho que molda a política por anos. Segundo D. Collier e R. Collier (1991, p. 29; 782), momento crítico é definido como: "um período de significativa mudança, que ocorre de modo diferente entre países (ou outras unidades de análise) a partir das rotas estabelecidas inicialmente que demarcam a produção de legados distintos". O momento crítico é uma situação de transição política e/ou econômica vivida por um ou vários países, estados, regiões, distritos ou cidades, caracterizado por um contexto de profunda mudança, seja ela revolucionária ou provocada por reforma institucional. Seu tempo de duração pode ser de anos ou até de décadas. Num momento crítico, o processo de mudança que se inaugura deixa um legado que conduz os políticos a escolhas e decisões sucessivas ao longo do tempo, visando à reprodução desse legado.

O trabalho de Lipset e Rokkan (1967) sobre a formação dos partidos e sistemas partidários na Europa foi um dos primeiros a utilizar a noção de momento crítico para identificar conjunturas históricas que produziram grandes clivagens sociais. Essas clivagens reproduziram-se dentro dos partidos e, uma vez eliminado o custo para iniciar a atividade partidária (start up costs), e superados os processos de expectativas adaptativas, os partidos são reproduzidos através do tempo, gerando o que Lipset e Rokkan (1967) denominaram de sistemas partidários congelados. Apesar de Lipset e Rokkan (1967) usarem a noção de momento crítico em seu estudo, é no importante trabalho de D. Collier e R. Collier (1991) que esta noção torna-se mais sistematicamente definida.

D. Collier e R. Collier (1991) analisam a emergência do movimento sindical na América Latina durante o início do século XX e suas diferentes formas de incorporação inicial, isto é, de legalização e institucionalização sancionadas pelo Estado. Os autores buscam compreender os diferentes legados deixados para o movimento sindical por esta incorporação inicial, em cada país analisado. Para tanto, desenvolvem uma exaustiva e complexa análise histórica comparada de oito países (Argentina, Brasil, Chile, Colômbia, México, Peru, Uruguai e Venezuela), utilizando dependência de trajetória ${ }^{4}$, e tendo o momento crítico como noção central para mapear o período de incorporação inicial do movimento sindical e seus diferentes legados em cada país. Para comparar os oito países, os autores procuram separá-los em pares, buscando identificar histórias comuns no tipo de incorporação inicial. Apesar de desenvolverem comparações por pares de países, buscaram também apontar similaridades e diferenças políticas não só entre os pares como dentro do próprio par de países. Os oitos casos estão divididos em dois grandes tipos de incorporação: 1. por meio de Estado, caso de Brasil (1930-1945) e Chile (1920-1931); e 2. por meio de partidos, com divisão em três subtipos: 2.1. mobilização eleitoral pelo partido tradicional, em que se inserem Colômbia (1930-1945) e Uruguai (1903-1916); 2.2. populismo

\footnotetext{
${ }^{4}$ Sobre o conceito de dependência de trajetória (path dependency), ver, entre outros, Fernandes (2002) e Pierson (2000).
} 
trabalhista - Argentina (1943-1955) e Peru (1939-1948); e 2.3. populismo radical - México (1917-1940) e Venezuela (1933-1948).

A utilização do conceito de momento crítico aqui neste trabalho busca identificar a conjuntura similar experimentada por Porto Alegre e Salvador, após a promulgação da Constituição de 1988, ao longo da década de 90 e início da primeira década do século XXI, com a instituição dos conselhos municipais como elemento obrigatório da política social brasileira. Procurar-se-á, aqui, observar como estas duas cidades vivenciaram, de forma diferente, este momento crítico em contextos políticos distintos. Por meio disso, verifica-se qual legado foi estabelecido nas duas cidades em virtude do seu contexto político, que estimulou ou não a institucionalização e organização dos conselhos no sentido de torná-los mais autônomos e independentes do executivo municipal.

\section{O momento crítico em Porto Alegre: hegemonia de uma elite política afeita aos conselhos}

No caso de Porto Alegre, com as três gestões consecutivas do Partido dos Trabalhadores ao longo de toda a década de 1990 (1989-1992; 1993-1996; 1997-2000), houve uma construção de apoio às atividades do conselho e dos grupos da sociedade civil que militaram pela reforma sanitária na cidade, como evidenciam os trabalhos de Cortes (1995), David (2005), Heidrich (2002). Daí a existência de uma elite política estimuladora de um comportamento participativo do seu conselho municipal de saúde, o que o tornou mais ativo e independente em relação à Secretaria de Saúde. Nos trabalhos de Cortes (1998; 1995), tem-se a evidência empírica qualitativa da construção de uma policy community no caso dos conselhos municipais de saúde da região metropolitana de Porto Alegre. Houve, no caso do Conselho Municipal de Saúde de Porto Alegre, a presença de lideranças políticas ligadas aos setores dos profissionais, dos trabalhadores e dos usuários, comprometidas com a efetiva participação social, o que terminou por estimular uma atuação mais ativa e independente do conselho nestes setores aqui citados. Cortes $(1998$; 1995) observa que a posição do dirigente público municipal no início dos anos 90, período de criação do Conselho Municipal de Saúde de Porto Alegre, vai reforçar a ação dos representantes dos profissionais, trabalhadores e de usuários da área de saúde, no sentido de tornar esses setores representativos mais efetivos, assegurando-lhes voz. Isso foi reforçado ao longo dos anos 90, criando uma rota dependente de atuação forte e independente dos setores representativos de profissionais, trabalhadores e usuários na conduta do conselho.

O diferencial partidário utilizado pelo PT à frente da Prefeitura de Porto Alegre ao longo dos anos 90, com as instituições e fóruns participativos, foi o "lema" de que era a gestão mais comprometida com esta questão da participação social do que qualquer outro partido ou coalizão. Assim podia se posicionar em qualquer eleição como o partido mais participativo e democrático. É claro que as lideranças políticas à frente da Prefeitura não declaram que o estímulo às instituições participativas é estratégico para seu desempenho eleitoral. Pelo contrário, evitam qualquer referência desta natureza, bem como qualquer referência partidária no que se refere ao estímulo de instituições como os conselhos municipais e, como no caso aqui abordado, o conselho municipal de saúde. O mesmo se deu na implementação do orçamento participativo - programa utilizado pelo PT como diferencial partidário competitivo (SCHNEIDER; GOLDFRANK, 2005; GOLDFRANK, 2003).

Ao longo da redemocratização, entre meados dos anos 80 e início dos 90, Porto Alegre teve partidos de 'direita' relativamente fracos, pois o PTB, o PFL (atual DEM) e o PDS (e seus sucessores) sempre obtiveram menos de um terço da Câmara Municipal, ainda que nos níveis estadual e federal figurassem melhor eleitoralmente. A disputa eleitoral na capital gaúcha ficou com três partidos: PT, PMDB e PDT, que competiam pelo mesmo eleitorado de centro-esquerda e de classe média baixa. No início dos anos 80 estes dois últimos partidos desfrutavam de raízes locais mais profundas que o PT; sobretudo o PDT, que possuía laços mais fortes com associações de bairro, além de gozar de uma posição dominante dentro dos sindicatos locais daquelas associações. O PT tinha apoio de algumas bases de sustentação nessas associações, porém, recebia mais apoio dos movimentos comunitários menos formalizados (BAIOCCHI, 2004). Nada mais racional, portanto, que, à frente da gestão municipal, aprofundasse a rota participativa que estava na agenda da redemocratização, uma vez que era um partido afeito a estes elementos da democratização da gestão pública brasileira. 
Foi, portanto, nesse contexto que as instituições e fóruns participativos deliberativos, tais como os conselhos municipais, ganharam estímulo na gestão municipal gaúcha - o que tornou sua dinâmica regular. Entretanto, o fato de os conselhos municipais terem sido estimulados pela elite local vinculada ao PT que esteve à frente da gestão municipal não assegura que os elementos ligados ao clientelismo estejam isentos da patronagem política nestes espaços. Apesar da importância desse aspecto, este trabalho não se debruça sobre ele.

\section{O momento crítico em Salvador: polarização política e elite pouco afeita aos conselhos}

No caso de Salvador, o grupo político ligado ao PFL (atual DEM) que governou a cidade durante a segunda metade dos anos 90 (1997-2000) e primeira metade da primeira década do século XXI (2001-2004) foi liderado pelo Senador Antônio Carlos Magalhães (ACM). Um político cujo padrão de administração pública foi sempre calcado num processo decisório fechado, e com uma liderança capaz de formar quadros tecnocráticos de perfil dinâmico e pragmático, porém pouco afeitos a mecanismos de participação, controle social ou parceria públicoprivado. Esse grupo político nunca esteve ligado às discussões da agenda da redemocratização no que se refere à gestão participava de políticas sociais ou política urbana oriundas da Constituição de 1988 (FERNANDES, 2004).

Importante ressaltar que o grupo político que compunha a Prefeitura entre os anos de 1993-1996, e que era de oposição ao grupo do PFL ligado à ACM, mostra-se mais sintonizado com a nova agenda de gestão pública com participação social oriunda da Constituição de 1988. A prefeita Lídice da Mata, do PSDB, à época, tinha uma história ligada à luta pela reforma urbana nos anos 80, sobretudo a questões de participação social e autonomia municipal, em virtude de, como vereadora entre 1982 e 1986 pelo PMDB, ter atuado ativamente na elaboração e aprovação de algumas leis importantes que criavam diversos mecanismos de participação social na gestão municipal (IVO, 2000). ${ }^{5}$

É, portanto, em um contexto de polarização política e de elite política na gestão pouco afeita à participação social que o conselho municipal de saúde de Salvador vai amadurecer ao longo dos anos 90. A modificação na estrutura do conselho em 2000 reforça, aqui, o argumento de que o Conselho Municipal de Saúde foi pouco estimulado pela gestão municipal do PFL em Salvador, no sentido se de tornar autônomo em relação ao executivo municipal à frente da Prefeitura. No ano de 2000, o então Prefeito Antônio Imabassahy enviou à Câmara Municipal, um projeto de lei visando reduzir de 32 para 16 o número de conselheiros e também definir que a presidência do conselho fosse ocupada pelo secretário municipal de saúde e, não mais, por meio de eleição dos conselheiros (MILANI, 2007). Isso se deu em virtude de o conselho, durante sua gestão, e antes da modificação da sua estrutura, questionar as contas da Secretaria de Saúde. Como o Prefeito não quis dialogar com o conselho, acabou por escolher uma saída pouco democrática, com a dissolução do conselho, a definição do Secretário Municipal como presidente, diminuição do número de membros e nomeação de novos conselheiros submissos ao secretário e ao Prefeito. Na gestão iniciada a partir de 2005, o CMS de Salvador aprovou um novo regimento regulamentado pela Lei 7017/2006, que prevê a eleição do presidente do conselho por meio de voto direto dos conselheiros em assembleia plenária.

\section{Considerações Finais}

No momento crítico, aqui analisado, de formação e consolidação dos conselhos municipais nas grandes cidades brasileiras, observou-se que a rota inicial tomada pelo CMS de Salvador foi contrária ao de Porto Alegre. Na capital baiana, o Conselho Municipal de Saúde é menos organizado, autônomo e independente em comparação com o de Porto Alegre. Parte da explicação que se procura dar aqui está nos distintos contextos políticos em

\footnotetext{
${ }^{5}$ São dessa época a Lei de Regionalização do Orçamento Municipal e a criação do Conselho Municipal do Desenvolvimento Urbano (CONDURB). Em 1983 sancionou-se a Lei no 3.345/83 - Lei do Processo de Planejamento e Participação Comunitária, que tornava a participação social uma atividade permanente na cidade. Em julho de 1984, foi editada a Lei de Ordenamento, Uso e Ocupação do Solo (Lei no 3.377/84), e em 1985 foi aprovada a Lei Orgânica do Município de Salvador (Lei no 3.572/85), antes, portanto, da exigência contida na Constituição de 1988. Em novembro de 1985 foi sancionada a Lei no 3.592/85, que dispõe sobre o enquadramento e a delimitação de Áreas de Proteção Sócio-Ecológica (APSE). Em dezembro de 1985, o conjunto de medidas acerca da participação e do controle social consolidou-se no Plano Diretor de Desenvolvimento Urbano de Salvador (PDDU), regulamentado pela Lei 3.525/85.
} 
que cada cidade esteve inserida ao longo deste momento crítico. Isso não implica afirmar que a cultura política em Salvador e Porto Alegre são diferentes, sendo a capital gaúcha mais cívica que a capital baiana. Para tanto seria necessária uma investigação mais profunda e com mais indicadores, relacionados, inclusive, à estrutura econômica e social das duas cidades e dos respectivos estados a que pertencem. São pequenas as diferenças entre os dois conselhos, oriundas dos diferentes contextos políticos experimentados nas duas cidades. Em Salvador, a elite política à frente do executivo em dois mandatos (1997-2000 e 2001-2004) era avessa à agenda de participação na gestão municipal, o que se refletiu sobre o Conselho de Saúde de Salvador no que se refere à sua autonomia e independência do executivo municipal. No momento de consolidação dos conselhos municipais no país, visto que estes começam a ser criados após a constituição no início dos anos 90, Salvador vai experimentar uma gestão que retrocede no sentido de tornar seu conselho municipal de saúde mais autônomo, abortando um processo de amadurecimento do conselho.

Já em Porto Alegre, a elite política à frente do executivo municipal possuía como diferencial partidário e eleitoral o estímulo aos fóruns participativos. O que criou condições para que o Conselho Municipal de Saúde se institucionalizasse e desenvolvesse, ao longo da década de 90 e início da primeira década do século XXI, uma dinâmica interna mais autônoma e independente em relação à Secretaria Municipal de Saúde. Isso foi importante para que o CMS/POA pudesse exercer suas funções constitucionais efetivas.

Outro elemento à guisa de conclusão refere-se ao papel realmente efetivo e estimulador da participação social dos conselhos. É alvo de questionamentos importantes e pertinentes, como no trabalho de Abers e Keck (2008), que, ao tratarem dos comitês de bacia no Brasil, analisam, sobretudo, o aspecto relacionado ao formato organizativo dos conselhos, e aí o problema da representação organizacional, que não estimula a efetiva participação do cidadão individual. Este talvez seja apenas o início de uma longa discussão sobre o formato institucional existente. Como considera Avritzer (2008), talvez seja mais oportuno pensar que o desenho das experiências participativas, seja dos conselhos municipais ou de orçamentos participativos, deva ser redefinido para que tenham continuidade. O papel da elite dirigente, no sentido de apoiar estas novas configurações, será fundamental. 


\section{Referências}

ABERS, Rebecca Neaera; KECK, Margaret E. Representando a diversidade: estado, sociedade e "relações fecundas" nos conselhos gestores. Cad. CRH, v. 21, n. 52, p. 99-112, abr. 2008.

AVRITZER, Leonardo (Org.). A Participação em São Paulo. São Paulo: EDUNESP, 2004.

A Participação Social no Nordeste. Belo Horizonte: Editora da UFMG, 2007.

. Instituições participativas e desenho institucional: algumas considerações sobre a variação da participação no Brasil democrático. Opin. Pública, v.14, n.1, p.43-64, jun. 2008.

ANDRADE, Ilza Araújo Leão. O desenho das Políticas Públicas e a Dinâmica de seus Conselhos Gestores: um Estudo Comparativo das áreas de saúde, assistência social e trabalho. In: ENCONTRO DA ANPOCS, 25., out. 2002, Caxambu. Anais... Caxambu/MG: ANPOCS, out. 2002.

BAIOCHHI, Gianpaolo (2004). Porto Alegre: The Dynamism of the Unorganized. In: Daniel Chavez e Benjamin Goldfrank (eds) The Left in the City: Participatory Local Governments in Latin America. London: Latin America Bureau, 2004.

BANDEIRA, Denílson; LUBAMBO, Cátia; MELO, Marcus André (Org.). Desenho institucional e participação política: experiências no Brasil contemporâneo. Petrópolis/RJ: Vozes, 2005.

CARVALHO, Juvenilda et al. Conselhos Municipais: sua contribuição para o desenvolvimento local. In: ENCONTRO ANUAL DA ANPAD, 25., 1999, Florianópolis. Anais... Florianópolis: ANPAD, set. 1999.

CARVALHO, Antônio I de. Conselhos de Saúde no Brasil: participação cidadã e controle social. Rio de Janeiro: IBAM/FASE.

CASTRO, Rocío. Gênero e Participação Cidadã para o Desenvolvimento Local: os Conselhos Municipais de SalvadorBahia. Organizações e Sociedade, v. 6, n. 16 set./dez. 1999.

COELHO, Vera Shattan; VERÍSSIMO, José. Considerações sobre o processo de escolha dos representantes da sociedade civil nos conselhos de saúde de São Paulo. In: AVRITZER, Leonardo (Org.). A Participação em São Paulo. São Paulo: EDUNESP, p.105-122, 2004.

COLLIER, David; COLLIER, Ruth. Shaping the political arena. Critical junctures, the labor movement, and regime dynamics in Latin America. Princeton, New Jersey: Princeton University Press, 1991.

CORTES, Soraya M. Vargas. Conselhos Municipais de Saúde: a possibilidade dos usuários participarem e os determinantes da participação. Ciência \& Saúde Coletiva, v. 3. n. 1. p. 5-17, 1998.

. User participation and reform of Brazilian Health System: the case of Porto Alegre. London: London School of Economics and Political Science, 1995.

CUNHA, Eleonora S.M. A efetividade deliberativa dos Conselhos Municipais de Saúde e de Criança e Adolescente no Nordeste. In: AVRITZER, Leonardo (Org.). A participação social no Nordeste. Belo Horizonte: Editora UFMG, p. 135$162,2007$.

DAL POZ, M. R.; PINHEIRO, R. A Participação dos Usuários nos Conselhos de Saúde e seus determinantes. Ciência e Saúde Coletiva, v. III, n. 1, 1998.

DAVID, Clarete. Representantes e representados: relação entre conselheiros usuários, sua entidades e dos espaços descentralizados do Conselho Municipal de Saúde. 2005. Dissertação. (Mestrado em Sociologia) - Programa de Pós-Graduação em Sociologia, Universidade Federal do Rio Grande do Sul, Porto Alegre, 2005.

DOIMO, Ana Maria. 1995. A Vez e a Voz Popular. Movimentos Sociais e Participação Popular no Brasil pós-70. Rio de Janeiro: Relumé-Dumará/ANPOCS.

FARIA, Claudia Feres. Sobre os determinantes das políticas participativas: a estrutura normativa e o desenho institucional dois Conselhos Municipais da Saúde e dos Direitos da Criança e do Adolescente no Nordeste. In: AVRITZER, Leonardo (Org.). A Participação Social no Nordeste. Belo Horizonte: Editora da UFMG, p.111-134, 2007.

FERNANDES, Antonio Sérgio A. Gestão municipal e participação social no Brasil: a trajetória de recife e salvador (1986-2000). São Paulo: Annablume/FAPESP, 2004. 
FERNANDES, Antônio Sérgio A.; BONFIM, Washington. A democratização da gestão municipal no Brasil: a abordagem teórica do objeto. In: Denílson Bandeira Coêlho; Cátia Lubambo; Marcus André Melo. (Org.). Desenho institucional e participação política: experiências no Brasil contemporâneo. Petrópolis/RJ: Vozes, p. 131-154, 2005.

FUKS, Mario. Participação e influência política no Conselho Municipal de Saúde de Curitiba. Revista de Sociologia e Política, Curitiba, v. 25, p. 47-61, 2004.

GOHN, Maria da Glória. Conselhos gestores e participação sócio-política. São Paulo: Cortez. Coleção Questões de Nossa terra, v. 84, 2001.

GOLDFRANK, Benjamin. Making Participation Work in Porto Alegre. In: BAIOCCHI (Ed.) Radicals in Power. London: Zed Books, 2003.

HEIDRICH, Andréa. A participação do Conselho Municipal de Saúde no processo de decisão sobre a política de saúde em Porto Alegre. Dissertação (Mestrado em Sociologia) - Programa de Pós-Graduação em Sociologia, Universidade Federal do Rio Grande do Sul. Porto Alegre, 2002.

IVO, Anette Leal. a política desejada e as certezas lógicas: o planejamento estratégico e o plano urbano em Salvador. In: Ivo, Anete Leal (Org.). O Poder da Cidade. Limites da Governança Urbana. Salvador: EDUFBA, p. 87-120.

LIPSET, Seymour Martin; ROKKAN, Stein. cleavage structures, party systems, and voter alignments: an introduction. In: Party Systems, and Voter Alignments: Cross National Perspective. New York: Free Press, p. 1-64, 1967.

MILANI, Carlos. Participação social e ação pública local na Bahia. In: AVRITZER, Leonardo (Org.). A participação social no Nordeste. Belo Horizonte: Editora da UFMG, p. 215-236, 2007.

PERISSINOTTO, Renato M; FUKS, M.; RIBEIRO, Ednaldo Aparecido. Cultura política e desigualdade: o caso dos conselhos municipais de Curitiba. Revista de Sociologia e Política, Curitiba, n. 21, p. 125-145, 2003.

PIERSON, Paul. Increasing Returns, Path dependency, and Study of Politics”. American Political Science Review, v. 94, n. 2, p. 251-267, June 2000.

Putnam, Robert. Comunidade e Democracia. A Experiência da Itália Moderna. Rio de Janeiro: Fundação Getúlio Vargas. (Tradução de Making Democracy Work: Civic Traditions in Modern Italy), 1993.

RAICHELIS, Raquel. Esfera pública e conselhos de assistência social: caminhos da construção democrática. São Paulo: Cortez, 2000.

SANTOS JR., Orlando Alves dos; RIBEIRO, Luiz César Queiroz; AZEVEDO, Sérgio. Democracia e Gestão Local: a Experiência dos Conselhos Municipais. In: Santos Junior, Orlando Alves dos; Ribeiro, Luiz César Queiroz; Azevedo, Sérgio (Orgs.). Governança democrática e poder local: a experiência dos conselhos municipais no Brasil. Rio de Janeiro: Revan/Observatório das Metrópoles/FASE, p.11-56, 2004.

SCHNEIDER, Aaron; GOLDFRANK, Benjamin. O PT e o Orçamento participativo no Rio Grande do Sul. In: BANDEIRA, Denílson; LUBAMBO, Cátia; MELO, Marcus André (Orgs.). Desenho institucional e participação política: experiências no Brasil contemporâneo. Petrópolis/RJ: Vozes, pp. 221-255, 2005.

TATAGIBA, Luciana. Os Conselhos Gestores e a Democratização das Políticas Públicas no Brasil. In: DANGNINO, Evelina (Org.). Sociedade civil e espaços públicos no Brasil. São Paulo: Paz e Terra, p. 47-103, 2002.

TÓTORA, Silvana; CHAIA, Vera. Conselhos Municipais: descentralização, Participação e Limites Institucionais. Cadernos Metrópole, n. 8, p. 69-102, 2. sem. 2002. 